\title{
Leadership Practice for Building Trust of Followers: Decisive Factors of Organizational Performance
}

\author{
Ba Phong Le 1 , Quang Thang Tran ${ }^{*}$ (i) \\ 1,2 Faculty of Business Management, Hanoi University of Industry, Bac Tu Liem, \\ Hanoi, Vietnam \\ * Corresponding author: thangktfuv@gmail.com
}

\section{Article History \\ Received 2020-02-19 \\ Revised 2020-03-02 \\ Accepted 2020-03-02 \\ Published 2020-03-04}

\section{Keywords \\ Transformational leadership \\ Organizational performance \\ Trust in leadership \\ Operational performance \\ Financial performance}

\section{How to cite?}

Le, B. P., \& Tran, Q. T. (2020).

Leadership Practice for Building Trust of

Followers: Decisive Factors of

Organizational Performance. SEISENSE

Journal of Management, 3(2), 45-57.

doi:10.33215/sjom.v3i2.308

Copyright (C) 2020 The Author(s)

(cc) BY
Purpose - Leadership plays a decisive role in key organizational outcomes. To investigate the effects of leadership and its mechanism on organizational performance, this paper examined how transformational leadership impacts followers' trust for improving operational and financial performance in the case of Vietnamese firms.

Design/Methodology - This study used the Structural Equation Modeling to assess the correlation among the constructs based on using survey data of 285 employees at 60 manufacturing and service companies.

Findings - The findings revealed that employees' trust in leadership acts as a mediating mechanism in the relationship between transformational leadership and organizational performance. The transformational leadership style of leaders has greater effects on financial performance, while employee's trust has larger effects on operational performance. This study calls attention to the importance of raising employee trust to link transformational leadership and organizational performance.

Practical and theoretical implications - From a practical point of view, the paper brings more knowledge and insights for $\mathrm{CEO} /$ managers on the right pathway to enhance organizational performance. The paper also provides theoretical initiatives on the leadership theory and the new pathway to promote operational and financial performance. 


\section{Introduction}

Organizational performance (OP) is critical to the firm's competitiveness and survival in today's competitive environment (Z. Wang, Sharma, \& Cao, 2016). Leader and their firms are trying to improve OP as an effective way to respond to the competition and change of business environment (Ramezan, Sanjaghi, \& Rahimian Kalateh, 2013). Organizational performance has become a significant issue and attracted much interest from many scholars (Brown, Gray, McHardy, \& Taylor, 2015). However, majority of the previous studies in this field pay particular attention to the effects of firm-level factors (such as capital, and labor inputs) in deciding organization performance without paying attention to the role of employee behavior which has clear impacts on OP, especially employee's trust in leaders (Brown et al., 2015). Moreover, after completely reviewing literature on the topic of leadership style, we recognized that transformational leadership (TL) is widely accepted as one of the most powerful leadership styles for key organizational outcomes (Ha, Phong, \& Hui, 2019; Le \& Lei, 2017, 2018a; Lei, Phouvong, \& Le, 2019). Transformational leaders motivate their employees to gain the highest levels of accomplishment for both managerial performance and OP (Garcia-Morales, Matias-Reche, \& Hurtado-Torres, 2008; Le \& Lei, 2018a; T. T. Nguyen, Mia, Winata, \& Chong, 2017). So, this study will illuminate the role and impact of TL on the trust of employees in their leaders aimed at improving OP.

As the aforementioned, TL and trust in leaders were found having a relationship with OP, there has been a insufficiency of study on how leadership links with aspects of employee's trust in leadership (Le \& Lei, 2018a; Le, Lei, \& Than, 2018) which in turn connects with components of OP namely operational and financial performance (Brown et al., 2015). This restricted our knowledge of the condition or mechanism according to which transformational leaders can establish the trust of employees in them and then effectively affect aspects of OP. For such reason, further theoretical or practical evidence on the relationship among these constructs is needful to solidify the relationship among them and generate valuable understanding for managers. Consequently, the paper is produced to elucidate TL's impacts on operational and financial performance via the mediating mechanism of specific types of trust in leadership. We believe that the paper will significantly contribute to increasing the leadership theory by clarifying how TL practice can stimulate employee's trust for the goal of enhancing OP. The paper will make an effort to address three research questions as follows.

- Does TL create significant impacts on OP?

- Does TL create different impacts on firm operational and financial performance?

- Do aspects of the trust of employees mediate the effects of TL on OP?

To address the research questions above, the paper applied structural equation modeling (SEM) to evaluate the extent of the effects of TL and employees' trust on specific elements of OP through the data of 285 respondents of 60 manufacturing and service companies in Vietnam. First, the paper conducts an adequate review of the related literature and provides the empirical proof for the correlation between TL, employees' trust in leadership, and OP in an integrated model. Second, the paper does not merely calculate the direct impacts of TL and employees' trust in leadership but also investigate clearer the TL's indirect influence on OP. In general, the paper is expected to bring specific initiatives and effectual directions for managers to boost operational performance and financial performance of firms.

\section{Literature Review}

\section{Transformational Leadership and Trust in Leadership}

Scholars defined transformational leadership as one of the styles of leadership to describe the features of leaders such as communicating clearly about organizational goals; serving as the leading factor of organization; involving actively in coaching employees; caring for improving new skills among employees and unendingly 
looking for new opportunities to bring the development for organization (Chen, Jermias, \& Lee, 2013; B. P. Le et al., 2018; Lei, Nguyen, \& Le, 2019). Transformational leaders value the role of the employees and view them as a decisive resource of the organization. They highly evaluate the significant roles of values, emotions, and leadership in fostering creative and positive behaviors of employees (Bass \& Avolio, 2000; Le \& Lei, 2017, 2019). Bass (1985) found that TL practice could not only inspire and prompt the followers to work beyond an organization's expectations but also promote an employee to attain their highest potential for organization development. For such reason, TL theory has appealed great interest among scholars and emerges as one of the most powerful leadership styles (Ha et al., 2019; Le \& Lei, 2018a). As a result, evaluating the influences of TL on aspects of employees' trust will bring more useful understandings for managers to develop employee's trust in them.

Trust expresses the level of belief of individuals on the other according to which they put their belief in the competence of the other as well as the willingness to act in a fair, ethical and predictable manner (Nyhan, 2000). According to Bligh (2017), trust can be seen as the individual's expectation or belief where he or she can rely on actions and words of the other, and believing that the other person has good intentions to carry out the promises. Scholars pointed out many types of trust of employees in organizations, for example, and organizational trust, interpersonal trust, trust in leadership, and peer trust (Joseph \& Winston, 2005; Le \& Lei, 2018a). However, to explore how TL practice can bring employees trust in leadership, this study focuses on examining the correlation between TL and aspects of trust in leadership. The findings of this investigation will bring significant managerial implications because successful leaders must have the ability to establish and maintain the trust of employees through giving employees the positive perceptions of their character and behavior(Bennis, Covey, Wheatley, \& Bogle, 2002).

According to Schoorman, Mayer, and Davis (2007), the trust of employees in leadership is their enthusiasm and willingness to take on vulnerability due to their positive expectations of the leader's intentions. Scholars separated trust in reliance-based trust and disclosure-based trust (Gillespie, 2003; Le \& Lei, 2018a). Where reliance-based trust reflects the readiness of individuals to rely on work-related skills, abilities, and knowledge of another and disclosure-based trust reflects the readiness of individuals to disclose work-related sensitive aspects, personal opinions, and information to another. This study uses these two aspects of individual trust to investigate the employees' trust in leadership because they lessen the risk and vulnerability which are inherent characteristics of trust (Le \& Lei, 2018b). In addition, these aspects of trust were specifically designed to calculate the decision or degree of employee trust in leadership (Dietz \& Hartog, 2006; Le \& Lei, 2017, 2018a).

Many prior studies provided support and evidence for the positive correlation between TL and the trust of employees in leadership. Harms and Credé (2010) found that transformational leaders are good mentors to nurture positive emotions and trustworthy culture in an organization. Scholar showed that if employees have an awareness of TL behavior in their leaders, they will have a higher degree of trust in their leadership (Holtz \& Harold, 2008). In particular notes, scholars revealed that leaders have very significant impacts on both aspects of employee's trust in them in term of disclosure-based trust and reliance-based trust (P. Lee, Gillespie, Mann, \& Wearing, 2010). Dirks and Ferrin (2002) reported the significant and positive effects of TL on the trust of employees in the leaders. According to MacKenzie, Podsakoff, and Rich (2001), TL practice by individualizing support and fostering acceptance of common goals will have a positive relation with trust in the leadership. Recently, Asencio (2016) argued that TL practice could motivate employees to follow and achieve the goals and vision of the organization, through which enabling leaders to develop employee trust in leaders by communicating attainable goals and an inspiring organizational vision. (Yasir, Imran, Irshad, Mohamad, \& Khan, 2016) also showed TL's positive influences on employee's trust in leaders.

In general, the above arguments provide supports for the clear influences of TL on trust in leaders. However, Le and Lei (2018b) indicated that there had been a shortage of research on how leadership links with aspects 
of trust in leaders. This limits our understanding of the different ways leaders may establish employee's trust in them (P. Lee et al., 2010). So, we propose the following hypotheses:

H1a.b: TL has positive impacts on disclosure-based trust and reliance-based trust in leadership.

\section{Transformational Leadership and Organizational Performance}

The OP has various meanings for different people because the essence of OP is multi-faceted (Ramezan et al., 2013). Moreover, measuring performance seems to be more complex due to the different expectations of stakeholders about the firm's economic, social, and environmental responsibilities change (Hubbard, 2009). According to Madella, Bayle, and Tome (2005), OP reflects the capability of an organization in acquiring and handling resources of finance and physic, and properly human aimed at achieving the key targets of the organization. Research of I. A. Lee (2008) considered OP as the result of implementing the strategy of an organization. It makes a deal of the output of an organization which measured against organizational intended objectives and goals. Tsai and Yen (2008) paid more attention to the roles of market and financial performance in evaluating OP. The current study uses operational and financial performance to evaluate $\mathrm{OP}$ as they are the crucial constituents of OP, and they have critical impacts on firm competitiveness and survival (Z. Wang et al., 2016). Regarding operational performance, it reflects the success in the mix and amalgamation of the customer satisfaction, cost management, quality development, responsiveness, and productivity; while financial performance manifests the capacity of a firm in using estates assets to bring about revenues as indicated by the financial statements of organizations (Z. Wang et al., 2016).

TL is a key factor that had apparent and positive influences on OP. Many previous types of research had explained for this conclusion (Bass, 1985; Garcia-Morales et al., 2008; Judge \& Piccolo, 2004; T. T. Nguyen et al., 2017; Pearce et al., 2003; Tushman \& Nadler, 1986). Specifically, according to Bass (1985), OP is fostered by transformational leaders' capabilities of motivating and inspiring individuals to work and attain outcomes beyond expectations. They build systems that provision direction, vitality, and energy to the organization, constituting good states and conditions for improving knowledge and innovation capability in the organization to promote OP (Tushman \& Nadler, 1986). Judge and Piccolo (2004) proved that transformational leaders have positive relationships with leader job performance and organizational performance, they primarily motivated followers toward the achievement of the goal in and of itself, with or without the rewards following the outcome (Pearce et al., 2003). Garcia-Morales et al. (2008) suggested that high performance in the organization is shaped by creating an organizational climate that is stimulated by the practice of TL. Recently, the meta-analytic study of scholars showed that TL was strongly and positively related to OP (G. Wang, Oh, Courtright, \& Colbert, 2011), and needed for better OP (Thomson, Rawson, Slade, \& Bledsoe, 2016). In line with these assessments, T. T. Nguyen et al. (2017) stated that TL influences OP by promoting incremental contributions of followers through exerting efforts further than the call of duty.

In short, the above discussions support the significant and positive impacts of TL on OP. Nevertheless, to bring deeper the understanding or knowledge of how TL affects operational and financial performance, we test the following hypotheses:

H2a.b: TL is positively associated with operational and financial performance.

\section{Trust in Leadership and Organizational Performance}

The trust among individuals is a core basis for confirming the effectiveness and success of an organization (Cook \& Wall, 1980). Many prior types of research have shown the evidence for the positive effects of employee's trust in leadership on firm performance (Asencio, 2016; Brown et al., 2015). Specifically, according to Dirks and Ferrin (2002) employees who have high trust in their leaders will become more comfortable to act in a way that may set them at risk in the relationship with their leaders due to sharing sensitive information or 
admitting mistakes. They also tend to satisfy their leaders by working hard on required tasks and performing beyond standards Dirks and Ferrin (2002), which in turn leads to increase OP. (Mayer \& Gavin, 2005) demonstrated that trust in leaders related to employee's ability to focus attention on value-producing activities which in turn have positive impacts on firm performance. Cho and Poister (2014) showed trust in leadership is directly related to firm performance or indirectly affect performance through teamwork. More specifically, Brown et al. (2015) provided insight into how trust in leaders can conduce to a participation and co-operation or reduce costly resistance to enhance productivity and firm performance. Their empirical findings showed a positive relationship between employee's trust in leaders and three measures of workplace performance: financial performance, labor productivity, and product or service quality. Most recently, Bligh (2017) study of leader and trust indicated that firm performance is one of the important outcomes of trust in leaders. Moreover, the existing empirical research also proposed that trust in leaders mediates the relationship between transformational leadership styles and firm performance (Asencio, 2016; Dirks \& Ferrin, 2002; Podsakoff, MacKenzie, Moorman, \& Fetter, 1990).

Although the above arguments showed the significant impacts of employee trust in leadership on OP, it is still a lack of study that investigated how aspects of employee trust in leadership are related to operational and financial performance, especially in the context of an emerging country like Vietnam. Accordingly, the following hypotheses are tested:

H3a.b.c.d: Disclosure and reliance-based trust of employees in leadership are significantly associated with operational and financial performance, respectively.

\section{Research Methodology}

\section{Sample and Data Collection}

The paper used a convenience sampling method to collect data during the period from May to September 2019. The survey data were gathered from 60 manufacturing and service companies in some most developed provinces of Vietnam, such as Danang, Hochiminh, and Hanoi. The authors have interacted with representatives of firms through the phone and making personal visits to explain and request their support for gathering the questionnaires. The participants need to be managers and team leaders to ensure having a full understanding of the constructs in the research. Measurement scales are collected from current literature to develop the initial list of items. Five hundred questionnaires were sent to participants and received back 320 ones. After removing invalid questionnaires, there were 285 valid ones, with a $57.0 \%$ validity rate.

\section{Variable Measurement}

Multiple items measure all the variables in this research. These items are calculated through five-point of Likert, which range from "1" to "5" (from strongly disagree to strongly agree or from strongly unwilling to strongly willing to).

Transformational leadership is calculated by four items origin from the research of (Garcia-Morales et al., 2008). Trust in leadership is calculated by ten items originated from the work of Gillespie (2003), which were also used by (Le \& Lei, 2018b). In which reliance-based trust is measured by five items to evaluate the perceptions of managers about "employees' willingness to rely on their work-related skills, abilities, and knowledge," and disclosure-based trust is measured by five items to evaluate the perceptions of managers about "employees" willingness in disclosing work-related sensitive aspects or personal opinions and information to the leaders" (Le \& Lei, 2018b). Finally, Organizational performance is measured by 11 items adapted from previous research (Z. Wang, Wang, \& Liang, 2014). OP is separated into operational performance and financial performance. Operational performance is calculated based on five items that evaluated the successful level of companies in obtaining "customer satisfaction, quality development, cost management, responsiveness, and productivity." 
Financial performance is measured by six items which estimate the capacity of companies in using assets to create revenues exhibited by their financial statements.

Control variables. Firm size is measured by several employees' acts as a controlling factor to account for variance among companies, and their potential influences on OP.

\section{Data Analysis and Results}

\section{Measurement Model}

The paper first examined the reliability of the measures for the constructs by examining the individual Cronbach's alpha coefficients $(\mathrm{C} \alpha)$, with the result's statistics ranging from 0.83 to 0.96 , which were all higher than the recommended level of 0.7 (Nunnally \& Bernstein, 1994).

The paper then performed a confirmatory factor analysis to assess convergent and discriminant validity. The paper adopted three primary measures to evaluate convergent validity (Hair, Black, Babin, Anderson, \& Tatham, 2006):

1. the factor loadings of latent variables must be statistically significant and higher than 0.6;

2. composite reliability (CR) needs to be higher than 0.7 , and

3. the average variance extracted (AVE) must be higher than 0.5.

Table 1 shows that all factor loadings are greater than 0.6 ; CR values exceed 0.7 , and the AVE values are greater than 0.5 . On the whole, all the measurements showed adequate convergent validity.

Table 1 -Convergent validity and reliability

\begin{tabular}{llllll}
\hline Construct & Mean & SD & AVE & CR & C $\alpha$ \\
\hline Transformational leadership (TL) & 3.48 & 0.51 & 0.56 & 0.83 & 0.83 \\
Reliance-based trust (RT) & 3.58 & 0.58 & 0.75 & 0.93 & 0.93 \\
Disclosure-based trust (DT) & 3.46 & 0.60 & 0.72 & 0.93 & 0.93 \\
Operational performance (OPP) & 3.71 & 0.61 & 0.82 & 0.96 & 0.96 \\
Financial performance (FIP) & 3.71 & 0.56 & 0.75 & 0.95 & 0.95 \\
\hline
\end{tabular}

Notes: $\mathrm{C} \alpha \geq 0.7$; composite reliability $\geq 0.7$; average variances extracted $\geq 0.5$; *** Significant at $\mathrm{p}<0.001$.

The authors continue using the measure of AVE as a suggestion of Fornell and Larcker (1981) to examine the discriminant validity by comparing the AVE's square root and the correlations among the latent constructs Table 2.

Table 2- Correlations and average variance extracted

\begin{tabular}{ccccccc}
\hline Constructs & TL & RT & DT & OPP & FIP & FS \\
\hline TL & $\mathbf{0 . 7 5}$ & & & & & \\
RT & 0.53 & $\mathbf{0 . 8 6}$ & & & & \\
DT & 0.52 & 0.48 & $\mathbf{0 . 8 5}$ & & & \\
OPP & 0.63 & 0.65 & 0.59 & $\mathbf{0 . 9 1}$ & & $\mathbf{0 . 8 7}$ \\
FIP & 0.64 & 0.59 & 0.58 & 0.60 & 0.05 & $\mathbf{1}$ \\
FS & 0.05 & 0.03 & 0.01 & 0.04 & \\
\hline
\end{tabular}

Note: Diagonal elements in bold are the square root of the AVE, and Off-diagonal elements are the correlations among constructs. 
Table 2 indicated that AVE's the square root of each factor (diagonal elements in bold) is higher than the correlations of the other factors in the research model. In other words, the results strongly support the construct reliability, convergent, and discriminant validity of the scales.

To assess the measurement model fit, this study evaluates the fit indicators of the CFA model. Table 3 indicated that all fit indices met satisfactory levels. Therefore, we can state that the model fits the data which can interpret the research hypotheses.

Table 3 - Overall fit index of the CFA model

\begin{tabular}{lcc}
\hline Fit index & Scores & Recommended threshold value \\
\hline Absolute fit measures & & \\
CMIN/df & 1.210 & $\leq 2^{\mathrm{a}} ; \leq 5^{\mathrm{b}}$ \\
GFI & 0.920 & $\geq 0.90^{\mathrm{a}} ; \geq 0.80^{\mathrm{b}}$ \\
RMSEA & 0.027 & $\leq 0.08^{\mathrm{a}} ; \leq 0.10^{\mathrm{b}}$ \\
Incremental fit measures & & \\
NFI & 0.953 & $\geq 0.90^{\mathrm{a}} ;$ \\
AGFI & 0.900 & $\geq 0.90^{\mathrm{a}} ; \geq 0.80^{\mathrm{b}}$ \\
CFI & 0.992 & $\geq 0.90^{\mathrm{a}} ;$ \\
\hline
\end{tabular}

Note: an Acceptability: acceptable; b Acceptability: marginal

\section{Direct Effect Analysis}

Figure 1 and Table 4 - Structural model results report that all the direct influences of TL and employees' trust in leadership on aspects of OP are quite large and statistically significant. So, all the proposed hypotheses are confirmed. Specifically:

For hypothesis H1a.b, the results showed that TL's influences on employee's trust in leaders are very strong. It also showed that there is no much difference in the effects of TL on two aspects of trust in leaders. Specifically, TL's impact on disclosure-based trust in leadership has coefficient value of 0.557 ( $\not$-value $<0.001)$, its impact on reliance-based trust in leadership has coefficient value of 0.565 ( $\not$-value $<0.001$ )

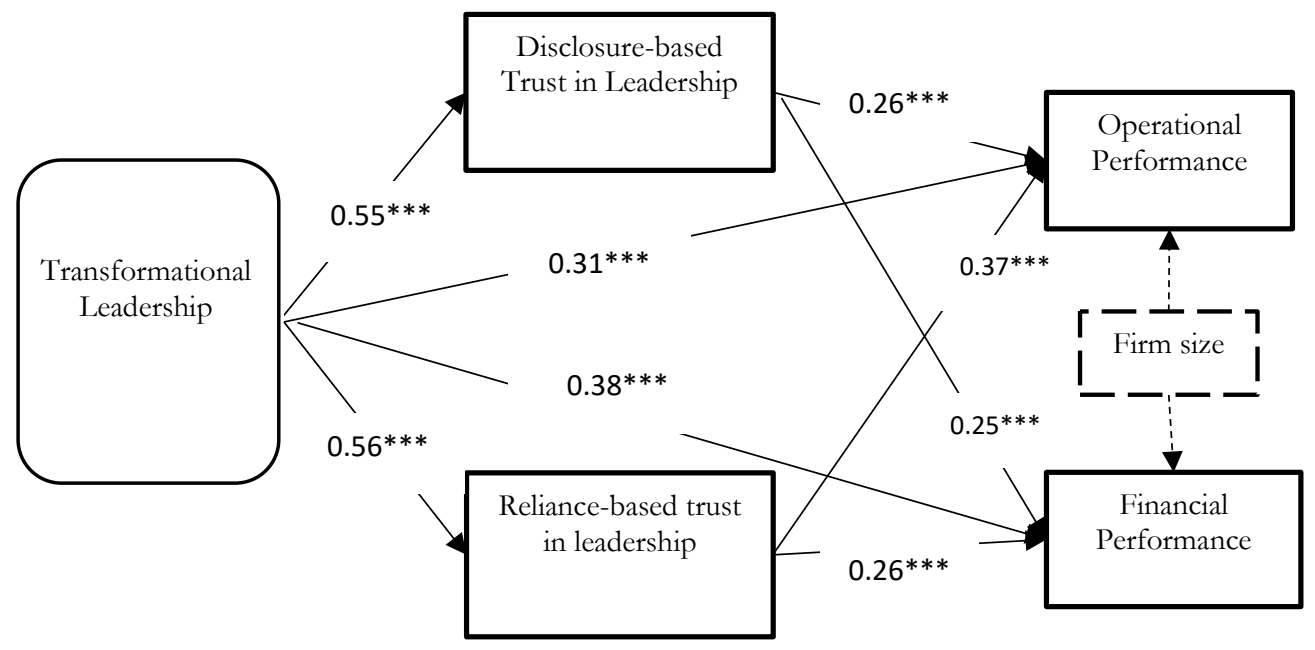

Figure 1 - The structural model

Note: *** $p<0.001 ;-----$ Non-signifiant paths. 
Table 4 - Structural model results

\begin{tabular}{lcllc}
\hline Hypotheses & Proposal effect & Estimate & $P$ & Results \\
\hline H1a: TL $\rightarrow$ DT & + & $0.557^{* * *}$ & $<0.001$ & Supported \\
H1b: TL $\rightarrow$ RT & + & $0.565^{* * *}$ & $<0.001$ & Supported \\
H2a: TL $\rightarrow$ OPP & + & $0.314^{* * *}$ & $<0.001$ & Supported \\
H2b: TL $\rightarrow$ FIP & + & $0.382^{* * *}$ & $<0.001$ & Supported \\
H3a: DT $\rightarrow$ OPP & + & $0.260^{* * *}$ & $<0.001$ & Supported \\
H3b: DT $\rightarrow$ FIP & + & $0.251^{* * *}$ & $<0.001$ & Supported \\
H3c: RT $\rightarrow$ OPP & + & $0.370^{* * *}$ & $<0.001$ & Supported \\
H3d: RT $\rightarrow$ FIP & + & $0.267^{* * *}$ & $<0.001$ & Supported \\
\hline Control variables & Effect & Estimate & P & Results \\
\hline FS $\rightarrow$ OPP & + & 0.012 & 0.769 & Not supported \\
FS $\rightarrow$ FIP & + & 0.028 & 0.514 & Not supported
\end{tabular}

Note: ${ }^{* * *}$ significant at the 0.001 level; ${ }^{* *}$ significant at the 0.005 level.

For hypothesis H2a.b, the results revealed that TL's influence on financial performance (coefficient value 0.382; $p$ value $<0.001$ ) is larger than its influence on operational performance (coefficient value of $0.314 ; p$ value $<$ $0.001)$.

For hypothesis H3a.b.c.d, the results showed that both disclosure-based trust and reliance-based trust in leaders have greater impacts on operational performance compared with financial performance. Specifically, disclosurebased trust influences operational and financial performance with coefficient values of 0.260 and 0.251 ( $\not$-value $<0.001)$, respectively. Reliance-based trust influences operational and financial performance with a coefficient value of 0.370 and 0.267 ( $p$-value $<0.001)$.

The results of the hypotheses tests were obtained after assessing the control role of firm size. The results did not support the control role of this variable because its effects on OP is not statistically significant (see Table 4).

\section{Indirect Effect Analysis}

To explain and show the evidence on the indirect effects or mediating mechanism of employee's trust in leadership, the paper performs bootstrap confidence intervals method as a recommendation of Preacher and Hayes (2008) to check for the indirect effect's extent and the statistical significance (Table 5).

Table 5 - Direct, indirect and total effects analysis

\begin{tabular}{cccccc}
\hline \multirow{2}{*}{ Path } & \multirow{2}{*}{$\begin{array}{c}\text { Direct } \\
\text { effects }\end{array}$} & \multirow{2}{*}{$\begin{array}{c}\text { Indirect } \\
\text { effects }\end{array}$} & \multirow{2}{*}{$\begin{array}{c}\text { Total } \\
\text { effects }\end{array}$} & & \multicolumn{2}{c}{\begin{tabular}{c} 
Bias-corrected confidence intervals \\
\cline { 5 - 6 } confidence level
\end{tabular}} & $\begin{array}{c}\text { Upper } \\
\text { confidence level }\end{array}$ \\
\hline TL $\rightarrow$ Trust $\rightarrow$ OPP & $0.314^{* * *}$ & $0.351^{* *}$ & 0.665 & 0.270 & 0.433 \\
TL $\rightarrow$ Trust $\rightarrow$ FIP & $0.382^{* * *}$ & $0.290^{* *}$ & 0.672 & 0.215 & 0.391 \\
\hline
\end{tabular}

Note: *** significant at the 0.001 level; ** significant at the 0.005 level.

Table 5 pointed out that the indirect impacts of TL on operational performance (value of 0.351 ) and financial performance (value of 0.290 ) are significant and lie in confidence intervals. Thus, Table 5 has confirmed the partial mediating influences of aspects of employees' trust in leadership in the TL-OP relationship. Moreover, the results also revealed that TL's total impact on financial performance is very significant, with a value of 0.672. It highlighted that the direct impact of TL on financial performance is very important (value of 0.382 ; $p$-value $<0.001)$. 


\section{Discussion}

OP demonstrates the organization's success in a competitive environment (Hurduzeu, 2015; Z. Wang et al., 2016). Leaders and employee trust in leaders involved in behaviors that contribute to the firm's achievement of goals Van Wart (2011) and firm performance (Brown et al., 2015). It is hard to imagine a situation with more risk and vulnerability than the relationship between leader and employees without trust (Bligh, 2017). Trust becomes more meaningful in situations when one party is at risk or vulnerable to another party. For this reason, it becomes extremely valuable in relationships between leaders and employees, who have different roles and different levels of status and power (Bligh, 2017). In this context, the hypotheses that were developed in this article makes important contributions to both practical and theoretical initiatives on OP as well as the field of organizational behavior relating to employee trust by following specific reasons.

First, by performing a complete and sufficient review of current literature of the factors in the proposed research model, the paper has brought deeper understanding and knowledge of the relationship between TL, employee trust in leadership, and OP. The findings indicate the significant influences of TL and aspects of trust in leadership on OP. The basic reason for these results originated from the validity and effectiveness of TL styles (Le \& Lei, 2018a; Thomson et al., 2016) and trust is a dynamic and interpersonal link between leaders and employees, so it is especially useful for creating a positive relationship between leaders and employees at the workplace (Bligh, 2017). The finding showed that TL has more significant impacts on financial performance in comparison with operational performance. In contrast, the results highlight that both aspects of trust in leaders have more impacts on firm operational performance compared with financial performance. Exploring and clarifying the relationships among leadership, trust, and OP will bring valuable and specific guidance and information for managers in leading and creating desired impacts on each aspect of OP. Based on the findings, some practical implications are proposed such as: To attain better financial goals (such as the return on investment and sales, the growth of profit and sales, and the average profitability) compared with the key competitor, $\mathrm{CEO} /$ managers need to pay great attention to practicing the TL style. Besides, to attain better firm's strategic goals (relating to customer satisfaction, quality development, cost management, responsiveness, and productivity) compared with the key competitor, $\mathrm{CEO} /$ managers need paying attention to build and maintain the employee trust strongly in them. However, both TL practice and building employee's trust have an important role in improving firm performance.

Second, by assessing the influences of TL on two aspects of trust in leaders in relation to OP, the article makes a considerable contribution to increasing knowledge of trust in leaders and OP. As disclosure-based trust and reliance-based trust in leaders reflect two different degrees of trust of an individual, which is "willing to disclose sensitive and important issues/information to the leaders" and "willing to rely upon ability/competence of the leaders." Two of these aspects of trust are specifically suitable to measure the difference of employee's behavior/attitude of trust in leaders, which help to reduce the vulnerability and risk that is inherent to trust (Dietz \& Hartog, 2006). The full understanding of employee's different aspects of trust towards leaders will create favorable and effective conditions to improve OP. The empirical results show that TL has strong impacts on both two kinds of trust in leaders, which in turn have positive and significant influences on two components of OP. The finding implicates that, "willing to disclose sensitive and important issues to the leaders" enables transformational leaders to make right decisions which is useful and beneficial for OP; "willing to rely upon ability/competence of the leaders" enables transformational leaders to execute effectively intended goals relating OP because their followers will readily implement the leader's plans for belief of success. From these findings, the article highlights the important role of trust in leaders. As a result, to increase OP, $\mathrm{CEO} / \mathrm{managers}$ need to increase awareness of the importance of building employee's trust in them by impacting the employee's positive perception of the leader's character Dirks and Ferrin (2002) such as valuing employees as a type of valuable asset and decisive resource of organization; caring for building and maintaining an emotional link with 
employees and unendingly motivating them to follow and attain higher values; acting as the ideal leader and leading factor in organization; always looking for new chances creatively to bring organization the success and development in long term.

Third, this article contributes to filling the theoretical gaps by connecting TL, aspects of trust in leaders and OP in a model as the previous research's implications for future research to assess more specifically the effects of leadership on aspects of trust in leaders P. Lee et al. (2010) and OP Hassan and Hatmaker (2015) as well as estimate employee trust's impacts on components of OP (Brown et al., 2015). The empirical findings verified the mediating roles of two aspects of trust in leaders in the relationship between TL and OP, and highlight that TL practices will yield significant effects to operational and financial performance directly or indirectly through improving two specific aspects of trust in leaders. The finding brings more deeply understanding for $\mathrm{CEOs/managers} \mathrm{about} \mathrm{the} \mathrm{necessary} \mathrm{factors} \mathrm{as} \mathrm{well} \mathrm{as} \mathrm{the} \mathrm{new} \mathrm{pathway} \mathrm{to} \mathrm{promote} \mathrm{operational} \mathrm{and} \mathrm{financial}$ performance.

Together with a significant contribution to the theory and practice, this research also has certain limitations. First, the paper utilizes the cross-sectional design, so it may have an ability which not reflects exactly causal relationships among the constructs in the long-run. A longitudinal study is needful to help us addressing this limitation and confirming the result of the study. Second, the results and the benchmarks in this article are strictly suitable only for Vietnamese contexts. Future research may implement in other contexts to provide a clear picture in terms of the relationship among these constructs. Third, recent research indicated that collaborative culture plays an important role in bringing firms key and positive outcomes (Lei, Le, \& Nguyen, 2017; D. K. Nguyen, Phong, \& Hui, 2019; Yang, Nguyen, \& Le, 2018) where leadership serves as decisive antecedent (Lei, Do, \& Le, 2019). Future research might bring a more valuable understanding of the determinant of OP by investigating how TL affects collaborative culture to improve OP.

Notwithstanding, the paper's findings have brought more insights and the theoretical initiatives on the relationship between TL, employees' trust, and OP. The paper has provided the empirical proofs that verified all proposal hypotheses and highlighted the significant roles of TL practice and employee trust in enhancing OP. In other words, the paper stresses the important roles of boosting TL style practices in building up the trust of employees in their leaders for strongly promoting organizations' operational and financial performance. Finally, the authors expected that future works would effectively address the limitations of current research and bring deeper insight into the roles and effects of TL and other determinants on OP.

Funding: This research is funded by Vietnam National Foundation for Science and Technology Development (NAFOSTED) under grant number 502.02-2019.300.

Conflicts of Interest: The authors declare no conflict of interest.

\section{References}

Asencio, H. (2016). Leadership, Trust and Organizational Performance in the Public Sector. Transylvanian Review of Administrative Sciences, 12(SI), 5-22.

Bass, B. M. (1985). Leadership and performance beyond expectations: Free Press; Collier Macmillan.

Bass, B. M., \& Avolio, B. J. (2000). MLQ: Multifactor leadership questionnaire: Mind Garden.

Bennis, W., Covey, S., Wheatley, M., \& Bogle, J. (2002). Focus on leadership: Servant leadership for the 21st century: New York: John Wiley and Sons.

Bligh, M. C. (2017). Leadership and Trust Leadership Today (pp. 21-42): Springer.

Brown, S., Gray, D., McHardy, J., \& Taylor, K. (2015). Employee trust and workplace performance. Journal of economic behavior \& organization, 116, 361-378. 
Chen, Y., Jermias, J., \& Lee, G. (2013). The Performance Implication of Goal Achievability in Incentive Contracts and Feedback. Paper presented at the CAAA Annual Conference.

Cho, Y. J., \& Poister, T. H. (2014). Managerial practices, trust in leadership, and performance: Case of the Georgia department of transportation. Public Personnel Management, 43(2), 179-196.

Cook, J., \& Wall, T. (1980). New work attitude measures of trust, organizational commitment and personal need non-fulfilment. Journal of occupational psychology, 53(1), 39-52.

Dietz, G., \& Hartog, D. N. D. (2006). Measuring trust inside organisations. Personnel review, 35(5), 557-588.

Dirks, K. T., \& Ferrin, D. L. (2002). Trust in leadership: meta-analytic findings and implications for research and practice: American Psychological Association.

Fornell, C., \& Larcker, D. F. (1981). Evaluating structural equation models with unobservable variables and measurement error. Journal of marketing research, 18(1), 39-50.

Garcia-Morales, V. J., Matias-Reche, F., \& Hurtado-Torres, N. (2008). Influence of transformational leadership on organizational innovation and performance depending on the level of organizational learning in the pharmaceutical sector. Journal of Organizational Change Management, 21 (2), 188-212.

Gillespie, N. (2003). Measuring trust in working relationships: the behavioral trust inventory. Paper presented at the Academy of Management Conference, Seattle, WA.

Ha, A. T. L., Phong, L. B., \& Hui, L. (2019). Leadership and Organizational Learning: The Determinants of Innovation Speed and Innovation Quality in Vietnamese Firms. Journal of Management and Strategy, 10(1), 29-37.

Hair, J. F., Black, W. C., Babin, B. J., Anderson, R. E., \& Tatham, R. L. (2006). Multivariate data analysis 6th Edition. New Jersey: Pearson Education.

Harms, P. D., \& Credé, M. (2010). Emotional intelligence and transformational and transactional leadership: A meta-analysis. Journal of Leadership \& Organizational Studies, 17(1), 5-17.

Hassan, S., \& Hatmaker, D. M. (2015). Leadership and performance of public employees: Effects of the quality and characteristics of manager-employee relationships. Journal of Public Administration Research and Theory, 25(4), 1127-1155.

Holtz, B. C., \& Harold, C. M. (2008). When your boss says no! The effects of leadership style and trust on employee reactions to managerial explanations. Journal of occupational and organizational psychology, 81(4), 777-802.

Hubbard, G. (2009). Measuring organizational performance: beyond the triple bottom line. Business strategy and the environment, 18(3), 177-191.

Hurduzeu, R.-E. (2015). The impact of leadership on organizational performance. SEA: Practical Application of Science, 3(1).

Joseph, E. E., \& Winston, B. E. (2005). A correlation of servant leadership, leader trust, and organizational trust. Leadership \& Organization Development Journal, 26(1), 6-22.

Judge, T. A., \& Piccolo, R. F. (2004). Transformational and transactional leadership: a meta-analytic test of their relative validity. Journal of applied psychology, 89(5), 755.

Le, B. P., Lei, H., Phouvong, S., Than, T. S., Nguyen, T. M. A., \& Gong, J. (2018). Self-efficacy and optimism mediate the relationship between transformational leadership and knowledge sharing. Social Behavior and Personality: an international journal, 46(11), 1833-1846.

Le, P. B., \& Lei, H. (2017). How transformational leadership supports knowledge sharing: Evidence from Chinese manufacturing and service firms. Chinese Management Studies, 11(3), 479-497.

Le, P. B., \& Lei, H. (2018a). The mediating role of trust in stimulating the relationship between transformational leadership and knowledge sharing processes. Journal of knowledge management, 22(3), 521-537.

Le, P. B., \& Lei, H. (2018b). The mediating role of trust in stimulating the relationship between transformational leadership and knowledge sharing processes. Journal of Knowledge Management. 
Le, P. B., \& Lei, H. (2019). Determinants of innovation capability: the roles of transformational leadership, knowledge sharing and perceived organizational support. Journal of knowledge management, 23(3), 527547.

Le, P. B., Lei, H., \& Than, T. S. (2018). How leadership and trust in leaders forster employees' behavior toward knowledge sharing. Social Behavior and Personality: an international journal, 46(5), 705-720.

Lee, I. A. (2008). Relationship between the use of information technology (it) and performances of buman resources management $(\mathrm{brm})$ : Alliant International University, San Diego.

Lee, P., Gillespie, N., Mann, L., \& Wearing, A. (2010). Leadership and trust: Their effect on knowledge sharing and team performance. Management learning, 41(4), 473-491.

Lei, H., Do, N. K., \& Le, P. B. (2019). Arousing a positive climate for knowledge sharing through moral lens: the mediating roles of knowledge-centered and collaborative culture. Journal of knowledge management, 23(8), 1586-1604.

Lei, H., Le, P. B., \& Nguyen, H. T. H. (2017). How Collaborative Culture Supports for Competitive Advantage: The Mediating Role of Organizational Learning. International Journal of Business Administration, 8(2), 73-85.

Lei, H., Nguyen, T. T., \& Le, P. B. (2019). How knowledge sharing connects interpersonal trust and innovation capability: The moderating effect of leadership support. Chinese Management Studies, 13(2), 276-298.

Lei, H., Phouvong, S., \& Le, P. B. (2019). How to foster innovative culture and capable champions for chinese firms: an empirical research. Chinese Management Studies, 13(1), 51-69.

MacKenzie, S. B., Podsakoff, P. M., \& Rich, G. A. (2001). Transformational and transactional leadership and salesperson performance. Journal of the Academy of Marketing Science, 29(2), 115-134.

Madella, A., Bayle, E., \& Tome, J. (2005). The organisational performance of national swimming federations in Mediterranean countries: A comparative approach. European Journal of Sport Science, 5(4), 207-220.

Mayer, R. C., \& Gavin, M. B. (2005). Trust in management and performance: Who minds the shop while the employees watch the boss? Academy of management journal, 48(5), 874-888.

Nguyen, D. K., Phong, L. B., \& Hui, L. (2019). Creating Competitive Advantage for Vietnamese Manufacturing and Service Firms: The Role of Collaborative Culture and Innovation Capability. International Journal of Business Administration, 10(2), 32-42.

Nguyen, T. T., Mia, L., Winata, L., \& Chong, V. K. (2017). Effect of transformational-leadership style and management control system on managerial performance. Journal of Business Research, 70, 202-213.

Nunnally, J. C., \& Bernstein, I. (1994). Elements of statistical description and estimation. Psychometric Theory 3 Edition, McGraw-Hill, New York.

Nyhan, R. C. (2000). Changing the paradigm: Trust and its role in public sector organizations. The American Review of Public Administration, 30(1), 87-109.

Pearce, C. L., Sims Jr, H. P., Cox, J. F., Ball, G., Schnell, E., Smith, K. A., \& Trevino, L. (2003). Transactors, transformers and beyond: A multi-method development of a theoretical typology of leadership. Journal of Management development, 22(4), 273-307.

Podsakoff, P. M., MacKenzie, S. B., Moorman, R. H., \& Fetter, R. (1990). Transformational leader behaviors and their effects on followers' trust in leader, satisfaction, and organizational citizenship behaviors. The Leadership Quarterly, 1(2), 107-142.

Preacher, K. J., \& Hayes, A. F. (2008). Asymptotic and resampling strategies for assessing and comparing indirect effects in multiple mediator models. Behavior research methods, 40(3), 879-891.

Ramezan, M., Sanjaghi, M. E., \& Rahimian Kalateh, H. (2013). Organizational change capacity and organizational performance: An empirical analysis on an innovative industry. Journal of Knowledge-based Innovation in China, 5(3), 188-212. 
Schoorman, F. D., Mayer, R. C., \& Davis, J. H. (2007). An integrative model of organizational trust: Past, present, and future. Academy of Management Review, 32(2), 344-354.

Thomson, N. B., Rawson, J. V., Slade, C. P., \& Bledsoe, M. (2016). Transformation and Transformational Leadership:: A Review of the Current and Relevant Literature for Academic Radiologists. Academic radiology, 23(5), 592-599.

Tsai, C. F., \& Yen, Y. F. (2008). A model to explore the mystery between organizations' downsizing strategies and firm performance. Journal of Organizational Change Management.

Tushman, M., \& Nadler, D. (1986). Organizing for innovation. California management review, 28(3), 74-92.

Van Wart, M. (2011). Dynamics of Leadership in Public Service: Theory and Practice . New York: ME Sharpe: Inc.

Wang, G., Oh, I.-S., Courtright, S. H., \& Colbert, A. E. (2011). Transformational leadership and performance across criteria and levels: A meta-analytic review of 25 years of research. Group \& Organization Management, 36(2), 223-270.

Wang, Z., Sharma, P. N., \& Cao, J. (2016). From knowledge sharing to firm performance: A predictive model comparison. Journal of Business Research, 69(10), 4650-4658.

Wang, Z., Wang, N., \& Liang, H. (2014). Knowledge sharing, intellectual capital and firm performance. Management Decision, 52(2), 230-258.

Yang, Z., Nguyen, V. T., \& Le, P. B. (2018). Knowledge sharing serves as a mediator between collaborative culture and innovation capability: an empirical research. Journal of Business \& Industrial Marketing, 33(7), 958-969.

Yasir, M., Imran, R., Irshad, M. K., Mohamad, N. A., \& Khan, M. M. (2016). Leadership styles in relation to employees' trust and organizational change capacity: evidence from non-profit organizations. Sage Open, 6(4), 2158244016675396. 